\title{
SCALE MODEL THRUSTER ACOUSTIC MEASUREMENT RESULTS
}

\section{Acoustical Society of America}

$166^{\text {th }}$ Meeting Session 2pNS

Noise, Physical Acoustics, and Structural Acoustics and Vibration: Launch Vehicle Acoustics

December 3, 2013

\author{
R. Jeremy Kenny \\ NASA Marshall Space Flight Center \\ Magda B. Vargas \\ All Points Logistics/ESTS Group
}




\section{Agenda}

- Overview

- Single Thruster

- Quad Thruster

- Single vs. Quad Comparison

- Solid vs. Liquid Comparison

- Conclusions

- Backup 


\section{Overview}

- Subscale rocket acoustic data is used to predict acoustic environments for full scale rockets

- Over the last several years acoustic data has been collected during horizontal tests of solid rocket motors

- Space Launch System (SLS) Scale Model Acoustic Test (SMAT) was designed to evaluate the acoustics of the SLS vehicle including the liquid engines and solid rocket boosters

- SMAT is comprised of liquid thrusters scalable to the Space Shuttle Main engines (SSME) and Rocket Assisted Take Off (RATO) motors scalable to the 5-segment Reusable Solid Rocket Motor (RSTMV)

- Horizontal testing of the liquid thrusters provided an opportunity to collect acoustic data from liquid thrusters to characterize the acoustic environments

- Acoustic data was collected during the horizontal firings of a single thruster and a 4-thruster (Quad) configuration

- Presentation scope

- Discuss the results of the single and 4-thuster acoustic measurements

- Compare the measured acoustic levels of the liquid thrusters to the Solid Rocket Test Motor V - Nozzle 2 (SRTMV-N2)

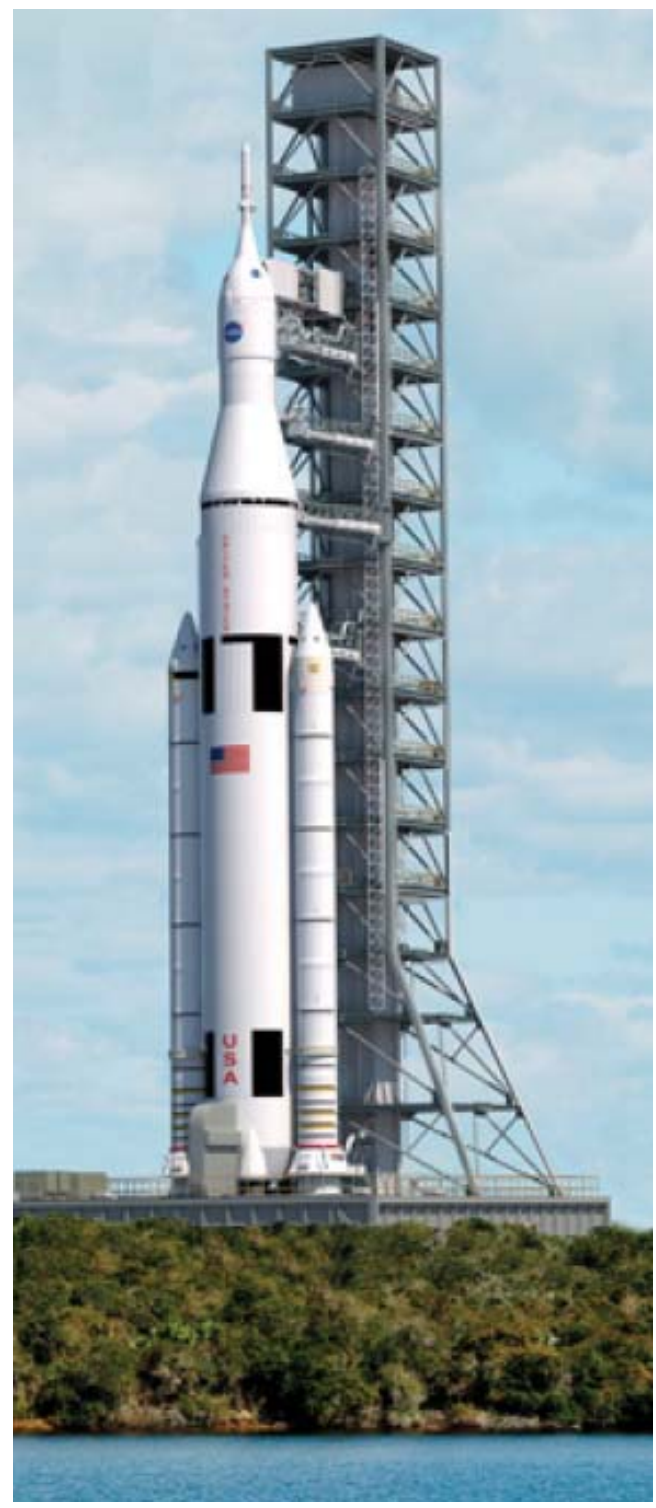




\section{Quad Thruster Video}




\section{Thrusters}

- Plume core length is approximately 13 nozzle exit diameters

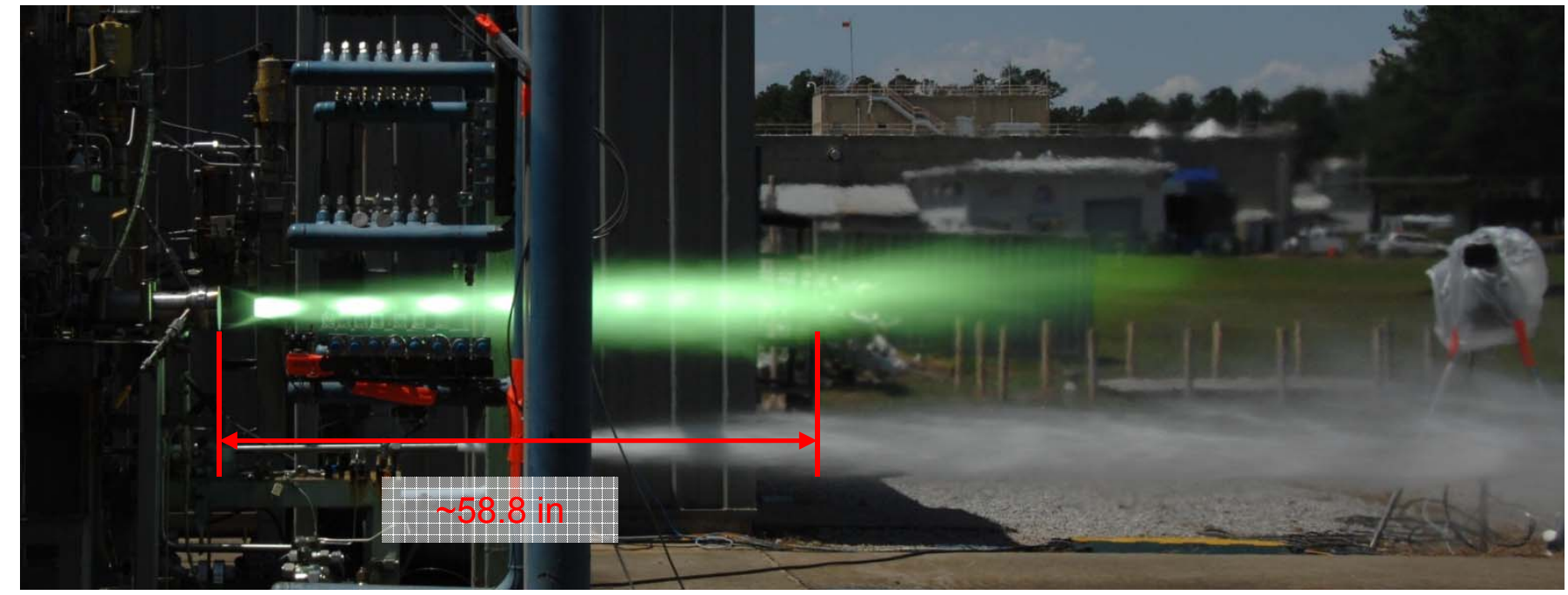

Single Thruster Test Firing

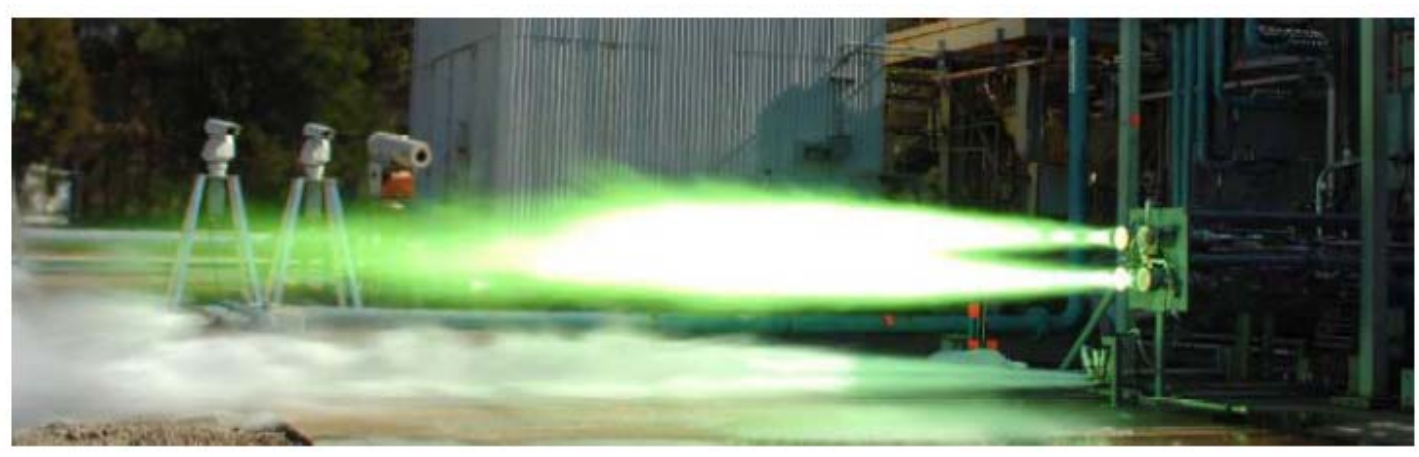

4-Thruster (Quad) Thruster Test Firing

R. J. Kenny / M. Vargas

JACOBS

5 


\section{Instrumentation Layout}

- Acoustic measurements were taken in an circular array layout at 80 nozzle exit diameters from the nozzle exit plane (effective NED used for the quad thruster)

- Single Thruster: $9.2 \mathrm{~m}$ circular array from 20 to 50 degrees in 10 degree increments

- Quad Thruster: 18.4 m circular array from 20 to 50 degrees in 10 degree increments

- STRMV-N2: 28.3 m circular array from 20 to 80 degrees in 10 degree increments

- Sensors were leveled with the nozzle exit elevation

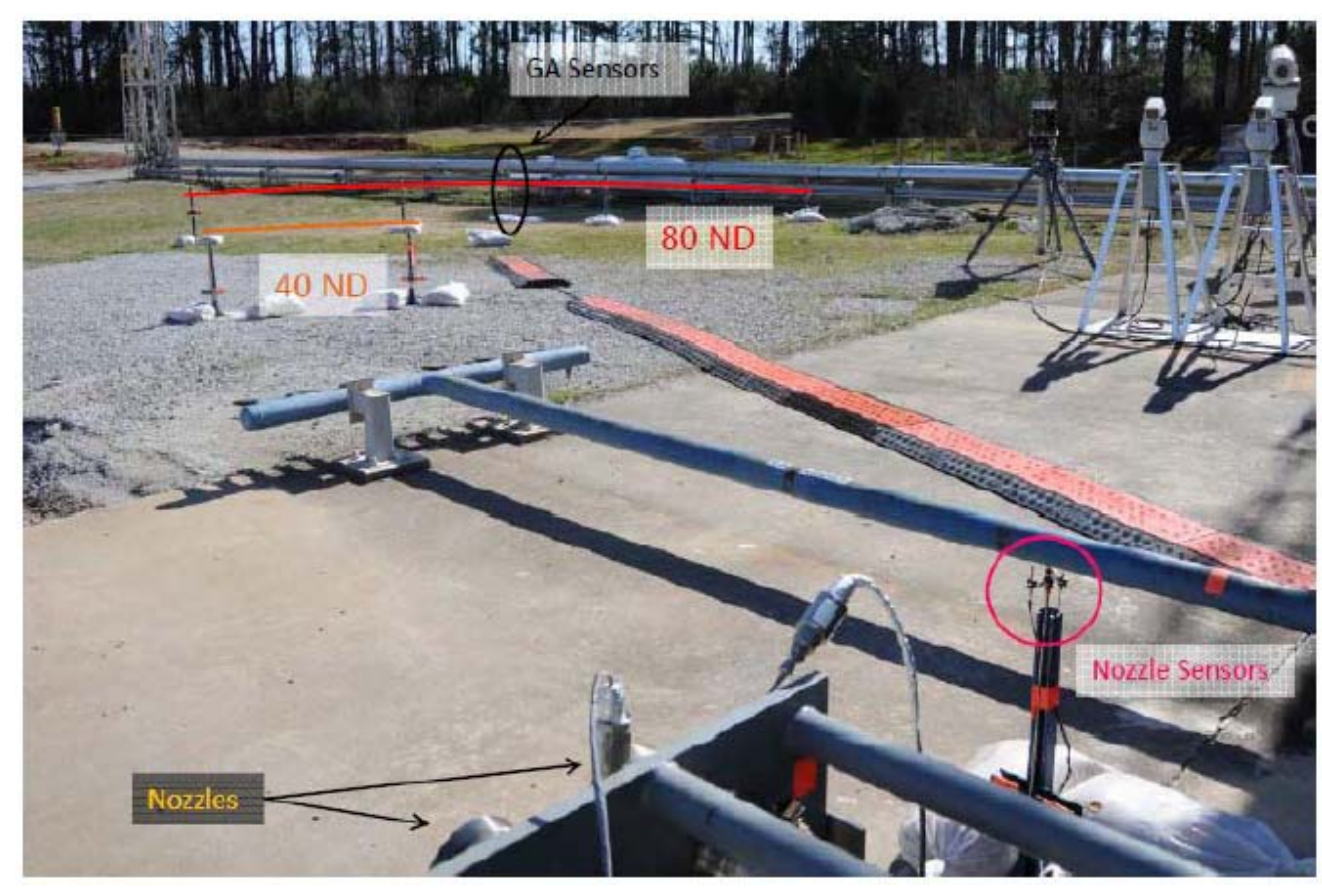

Quad Thruster Acoustic Instrumentation

$$
\text { R. J. Kenny / M. Vargas }
$$




\section{Instrumentation Layout}

- Terrain and test stand structures limited the amount of measurements that could be setup for the array

- 4 measurements at 80 ND for thruster

- 7 measurements at $80 \mathrm{ND}$ for the SRTMV-N2

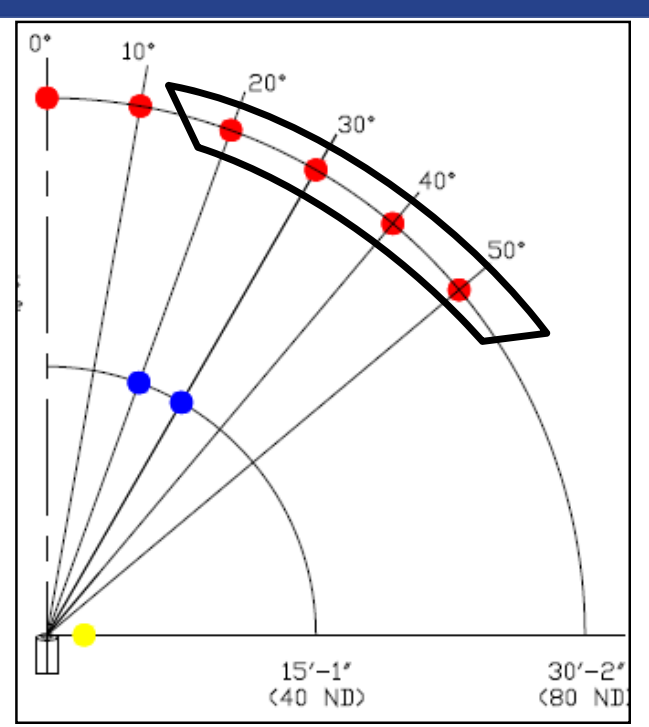

Single Thruster Instrument Layout

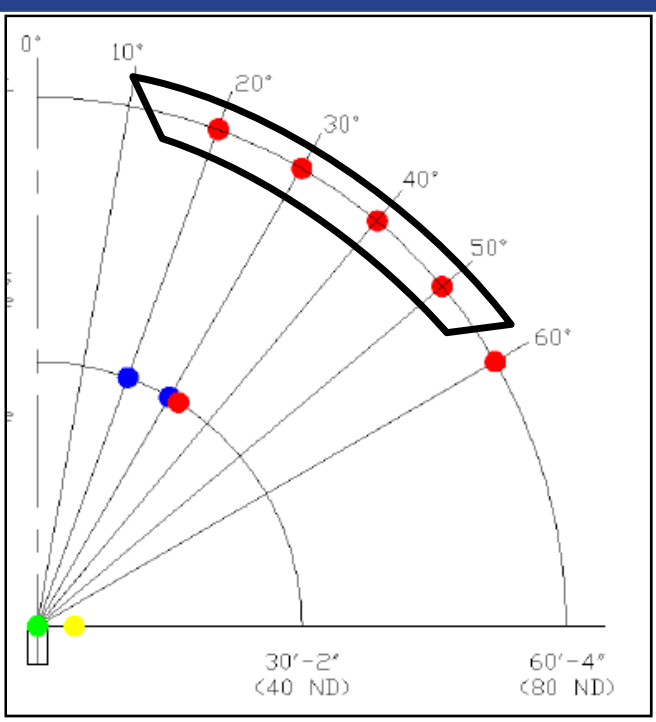

Quad Thruster Instrument Layout

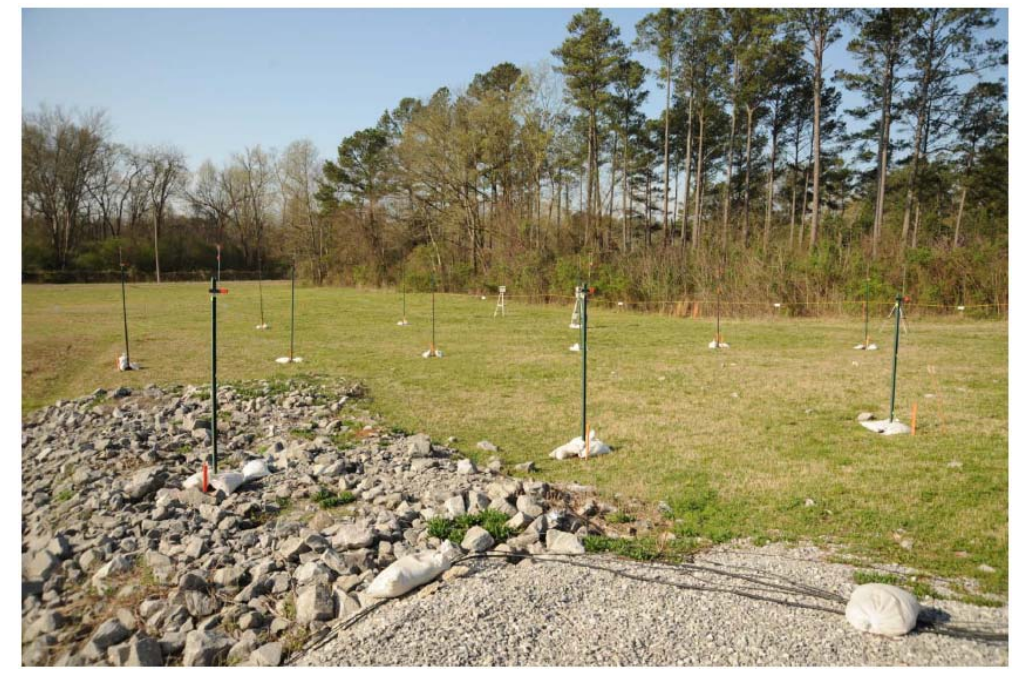

SRTMV-N2 Acoustic Instrumentation

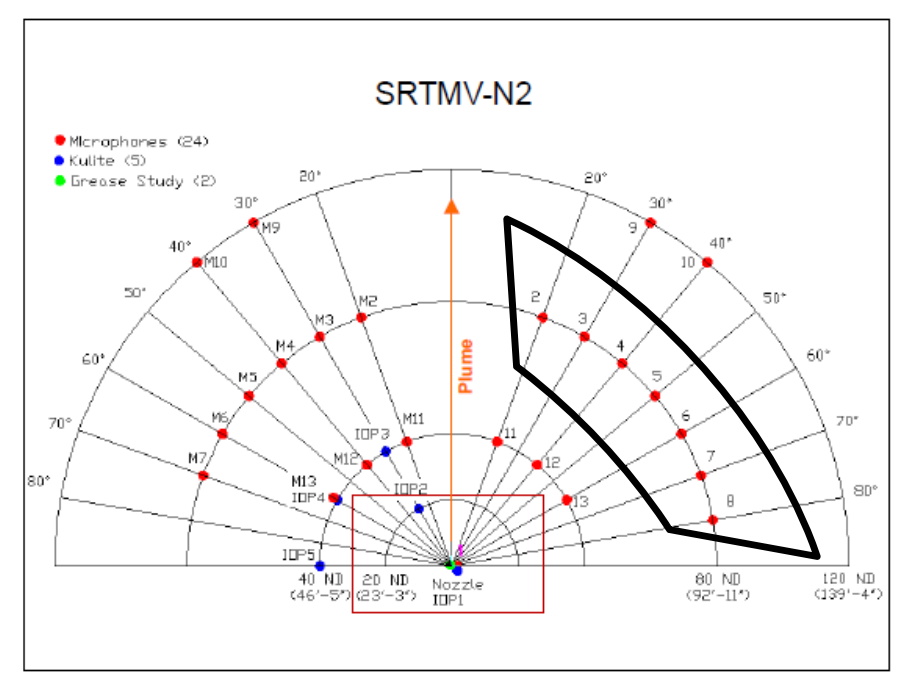

SRTMV-N2 Instrument Layout 


\section{Single Thruster SPL}

- Single thruster main stage burn time between 10 and 20 seconds

- Steady thrust levels throughout the main stage burn

- Measured sound pressure levels follow the thrust levels

- Overall SPL evaluated during a 4.6 second time window

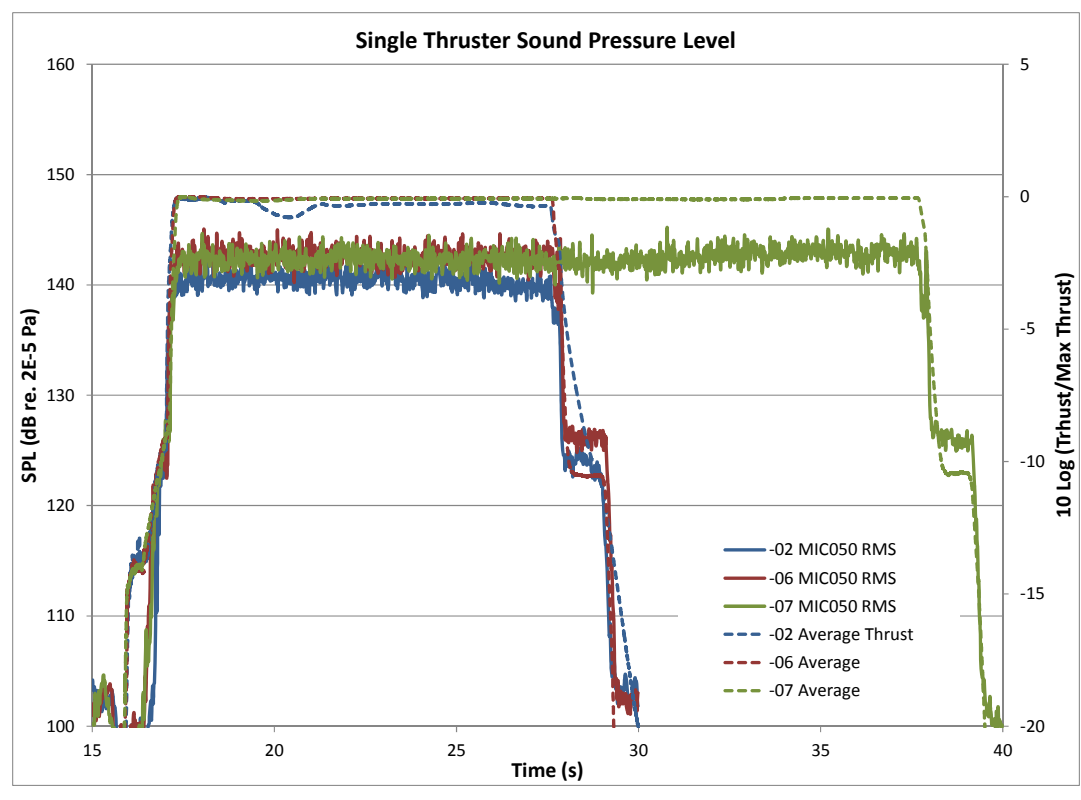

Single Thruster Test Sound Pressure Level and Thrust

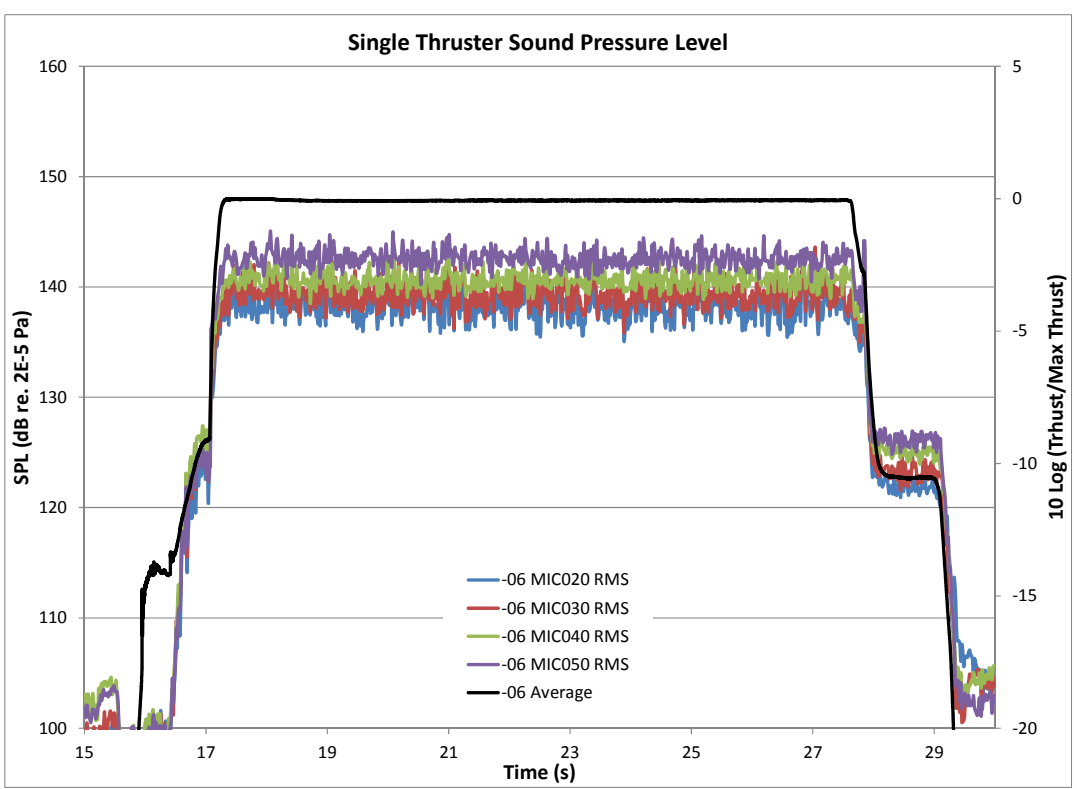

Single Thruster Test 780 psi Sound Pressure Level and Thrust per Receiver Angle 


\section{Single Thruster - 1/3 Octaves}

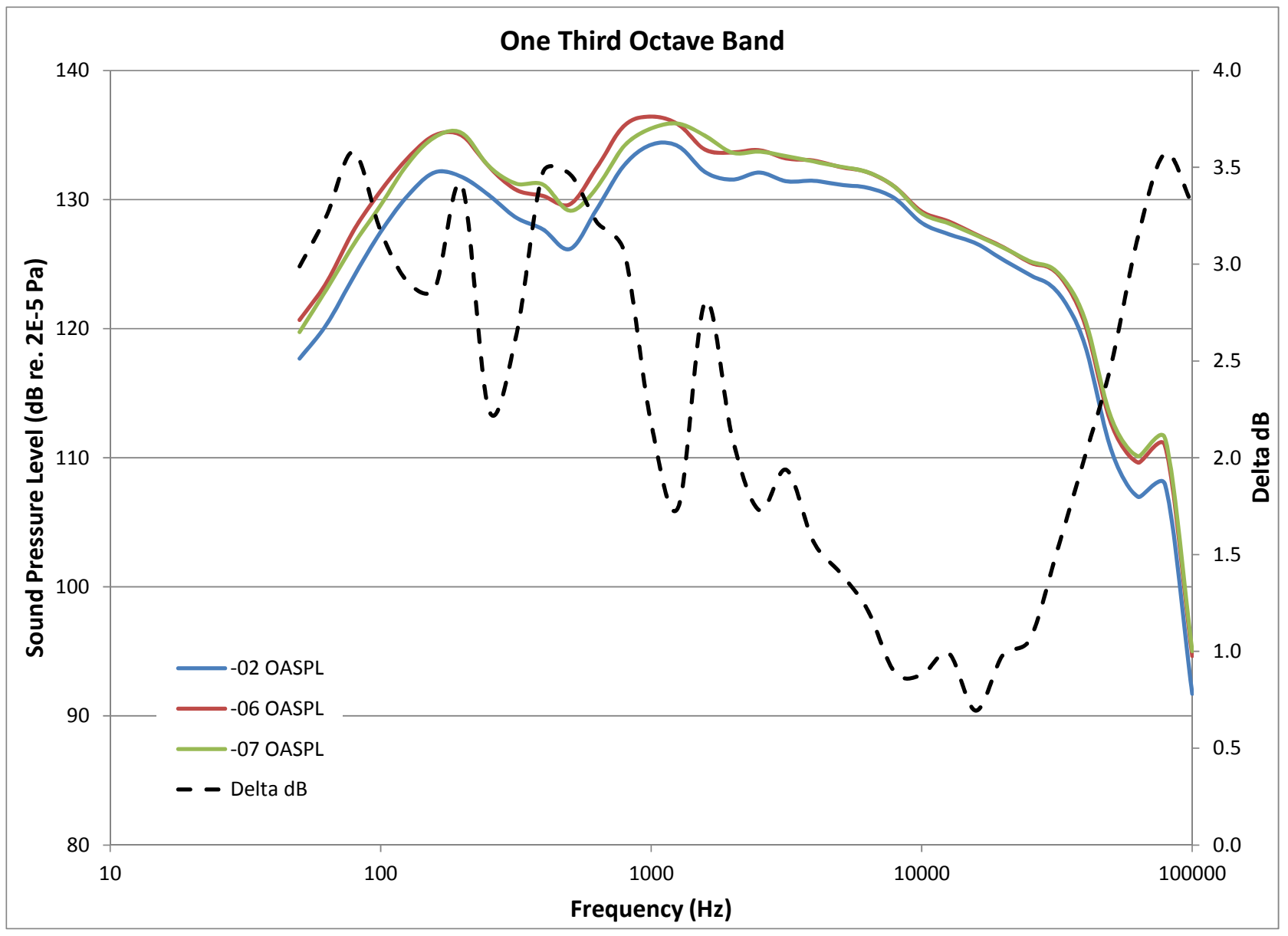

- Three single thruster measurements at different pressure levels show similar OASPL trends

- Maximum of $3.5 \mathrm{~dB}$ spread between the three measurements

- Expected delta dB due to the chamber pressure level $\sim 1.5 \mathrm{~dB}$ 


\section{Quad Thruster}
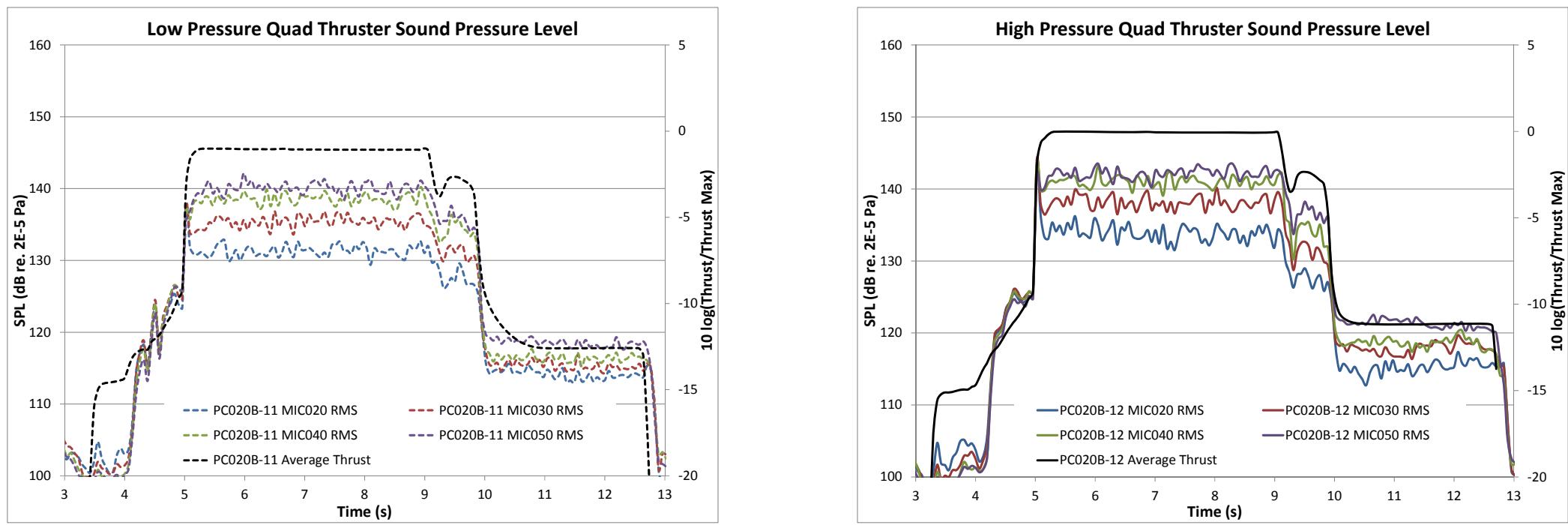

- Quad thruster main stage burns between 2 and 8 seconds

- Thrust levels are steady throughout the main stage burn

- Sound pressure levels follow the thrust levels

- Overall SPL evaluated during a 2.4 second time window

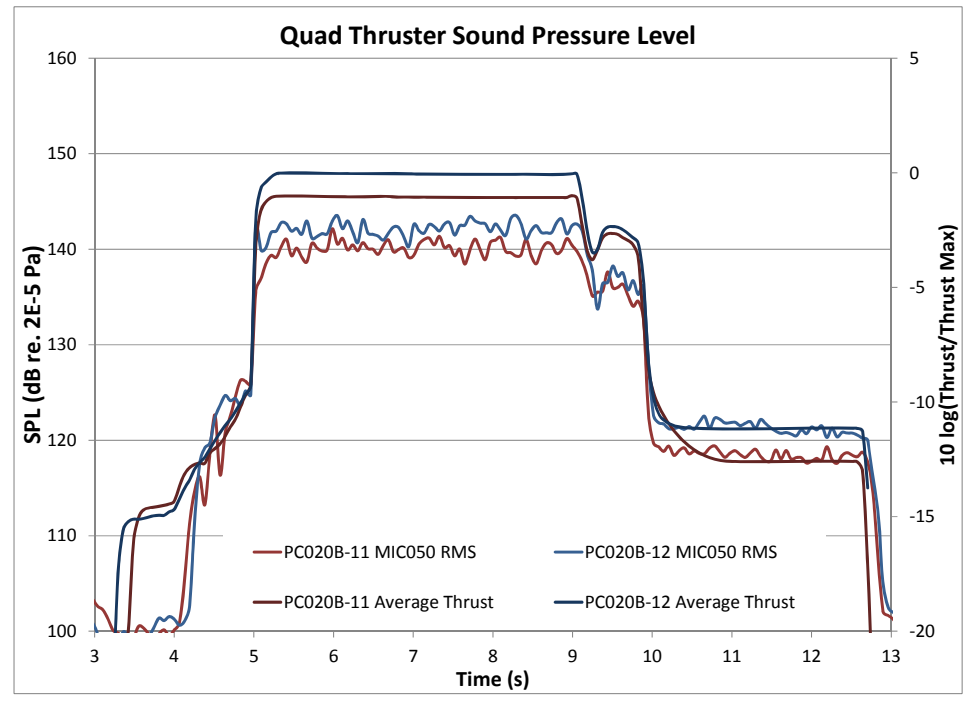




\section{Quad Thruster}
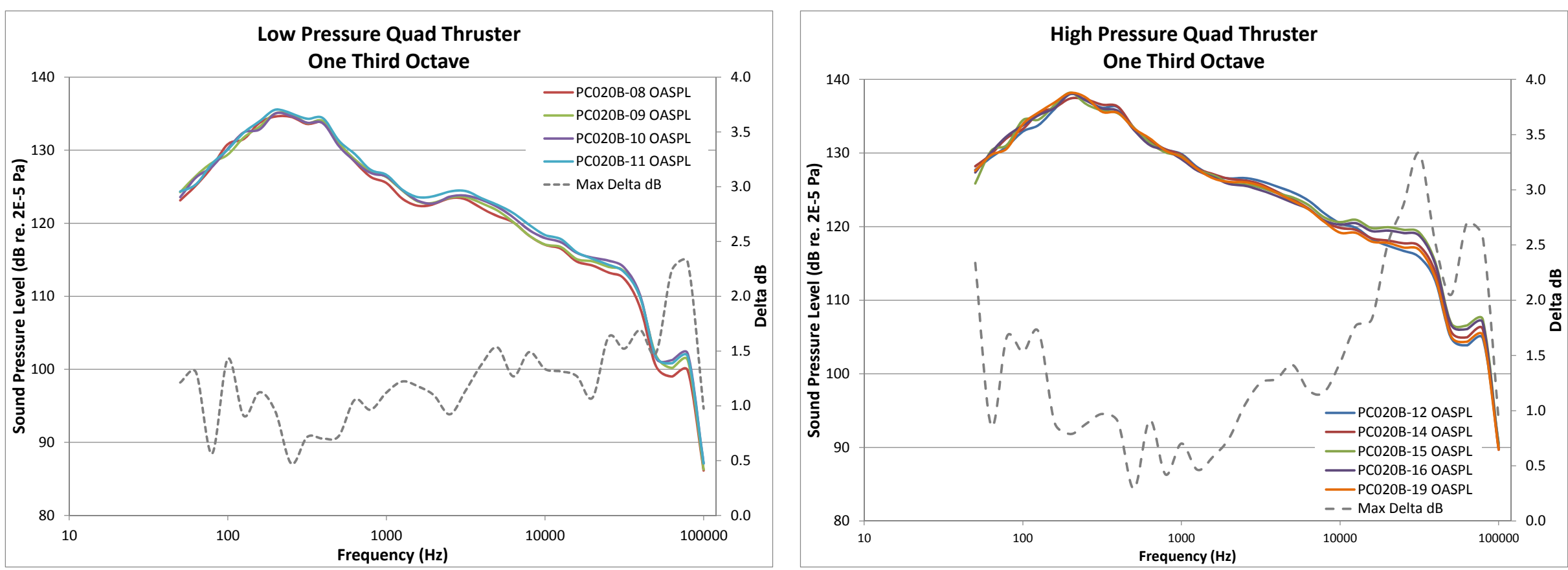

- Sound pressure level trace is repeatable for the quad thrusters at the two thrust levels

- Low thrust sound pressure levels shows a spread of less than $2.5 \mathrm{~dB}$

- Maximum of $3.5 \mathrm{~dB}$ spread at $30 \mathrm{kHz}$ in the high pressure thruster test series 


\section{Scaling}

- Single and quad thruster sound pressure levels were adjusted to the SRTMV-N2 sound pressure level

- Frequency was non-dimensionalized using the Strouhal number

$$
\text { Strouhal number }=\frac{f D_{e}}{V_{e}}
$$

- Amplitude scaling based on sound intensity

$$
\text { Adjusted SPL=SPL+10 } \log \left(\frac{l_{2}}{l_{1}}\right) \quad \frac{l_{2}}{l_{1}}=\frac{\eta_{2}}{\eta_{1}} \frac{\dot{m}_{2}}{\dot{m}_{1}}\left(\frac{V_{2}}{V_{1}}\right)^{2}\left(\frac{R_{1}}{R_{2}}\right)^{2}
$$

\begin{tabular}{|c|c|c|c|c|c|}
\cline { 2 - 6 } \multicolumn{1}{c|}{} & Single 555 & Single 780 & Quad 550 & Quad 710 & SRTMV-N2 \\
\hline De $(\mathrm{m})$ & 0.11 & 0.11 & 0.23 & 0.23 & 0.35 \\
\hline Ve $(\mathrm{m} / \mathrm{s})$ & 3,986 & 4,038 & 3,981 & 4,019 & 2,360 \\
\hline$\eta$ & $0.20 \%$ & $0.20 \%$ & $0.20 \%$ & $0.20 \%$ & $0.52 \%$ \\
\hline$\dot{\mathrm{m}}(\mathrm{kg} / \mathrm{s})$ & 1.16 & 1.58 & 4.29 & 5.62 & 33 \\
\hline $\mathrm{R}(\mathrm{m})$ & 9.2 & 9.2 & 18.4 & 18.4 & 28.0 \\
\hline Thrust $(\mathrm{N})$ & 4,626 & 6,361 & 17,094 & 22,584 & 77,444 \\
\hline$\Delta S P L$ & 4.49 & 3.05 & 4.84 & 3.59 & 0.00 \\
\hline OAPWL & 165.7 & 167.1 & 177.4 & 178.6 & 179.8 \\
\hline
\end{tabular}




\section{Quad Thruster Data}

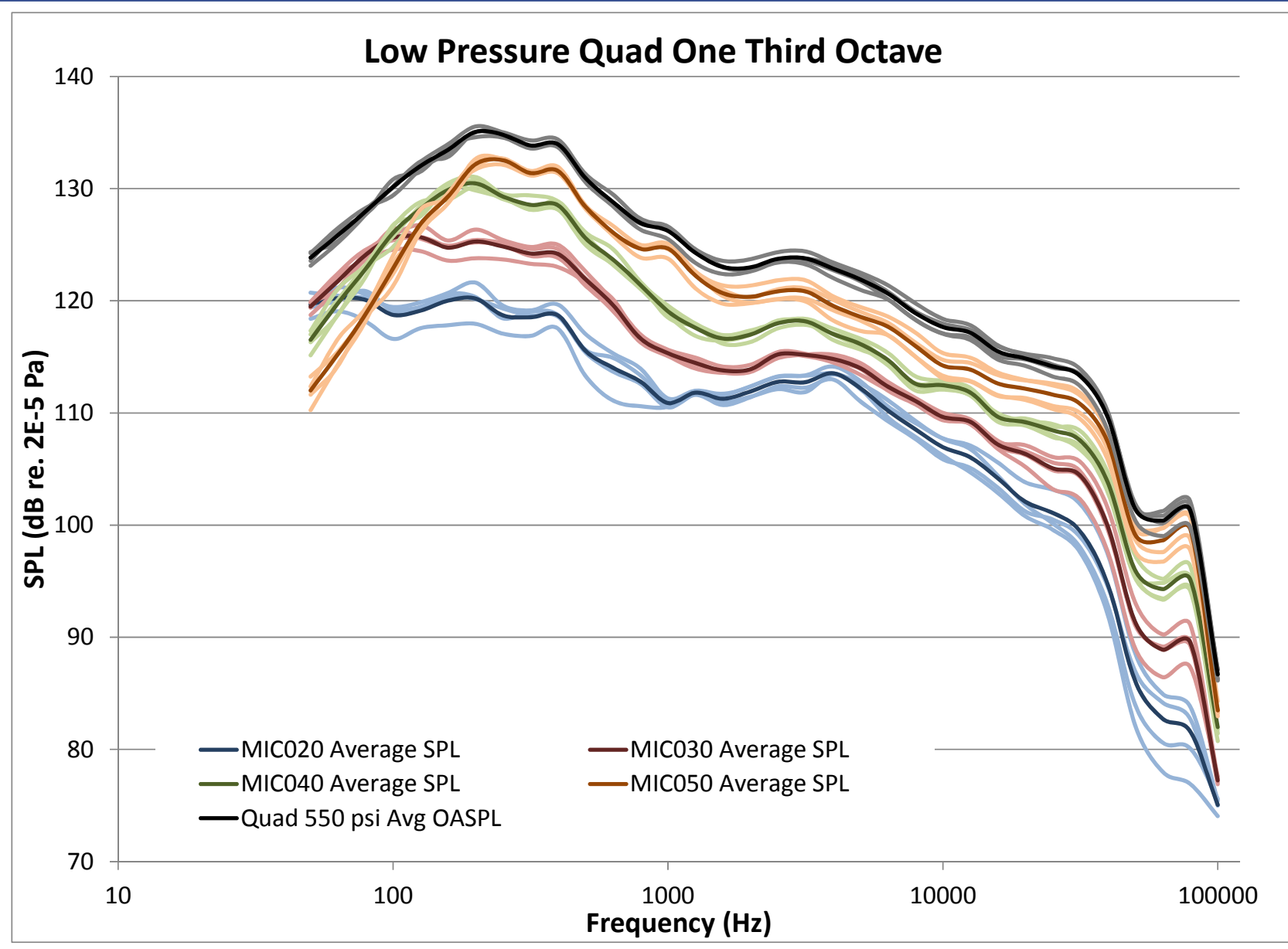

- Measurements are within $3 \mathrm{~dB}$ of each other up to $20 \mathrm{kHz}$ for all receiver locations at both pressure levels

- Average OASPL for each thrust level was used to scale the quad thruster measurements based overage SPL at each receiver location 


\section{SRTMV-N2 Summary}

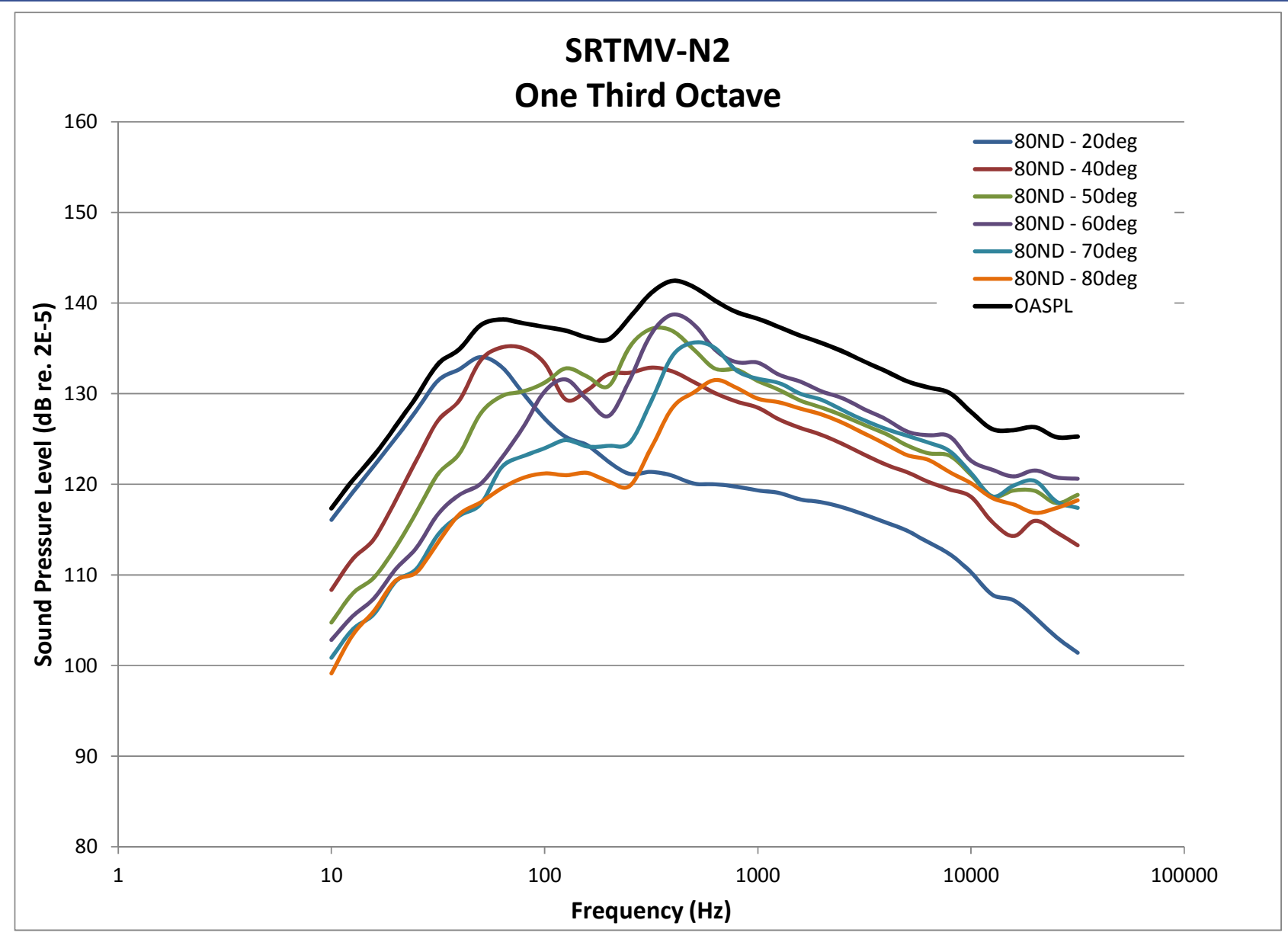

- Receivers located in a circular array between 20 and 80 degrees from the plume centerline

- More data points available to calculate the overall sound pressure level

- Both single and quad thruster sound pressure levels were scaled to SRTMV-N2 levels 


\section{Adjusted Data}

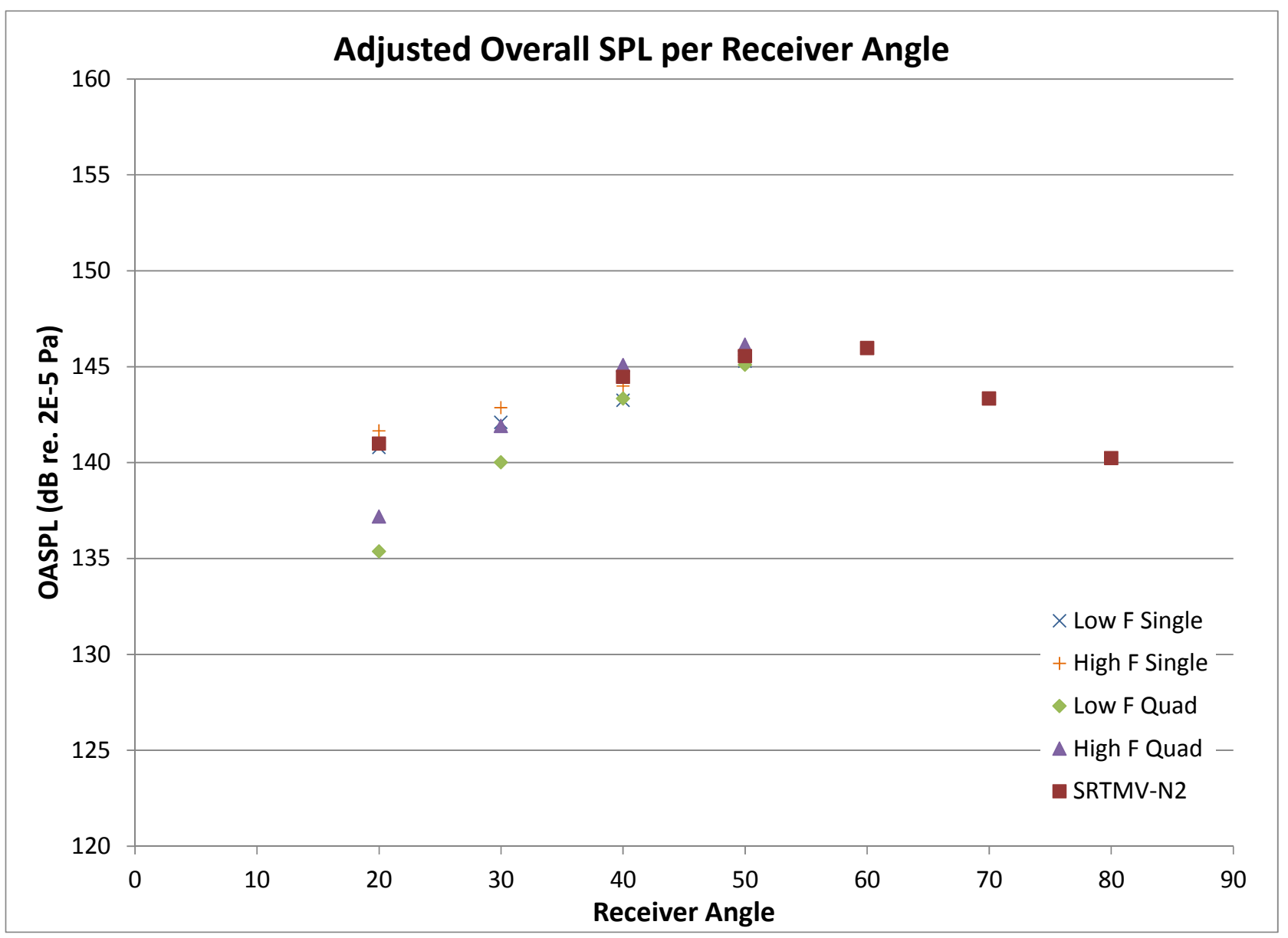

- Maximum spread is $6 \mathrm{~dB}$ at the 20 degree receiver

- Below $3 \mathrm{~dB}$ spread for the receivers at 30, 40 and 50 degrees 


\section{Adjusted Data}

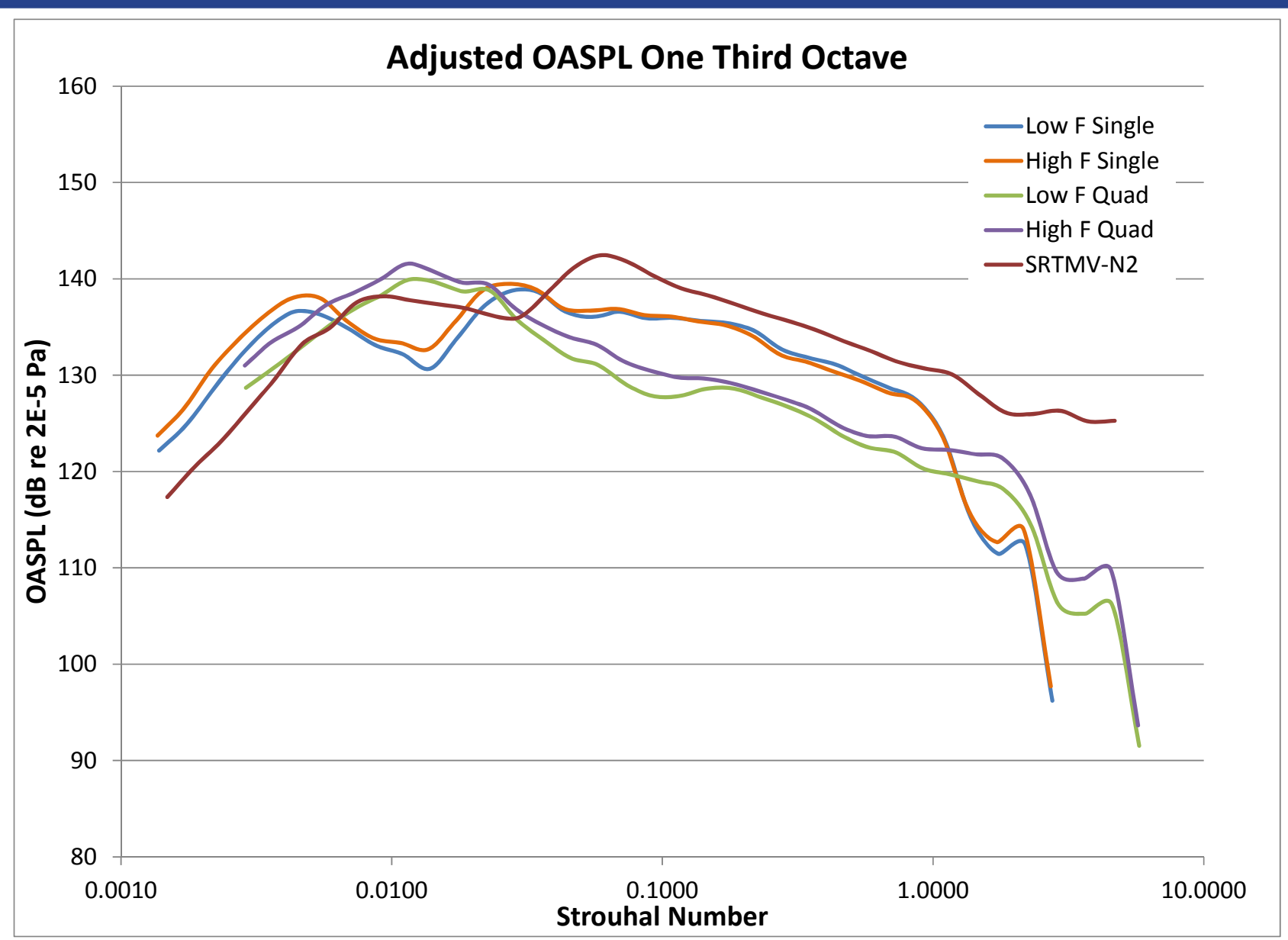

- Liquid thruster data peaks at a lower frequency than the solid motor

- Solid motor shows a higher SPL at the high frequencies possibly due to the high angle measurements

- Approximately $3.5 \mathrm{~dB}$ spread between the overall sound pressure levels

$$
\text { R. J. Kenny / M. Vargas }
$$




\section{Conclusions and Forward Work}

- Conclusions

- Liquid engine measurements are repeatable within $3 \mathrm{~dB}$ up to $20 \mathrm{kHz}$

- Overall sound pressure level spread between solid motor and liquid thruster is approximately $3.5 \mathrm{~dB}$

- Liquid thruster seems to peak at a lower frequency than the solid motor

- Dataset provides a subscale liquid dataset for empirical prediction models

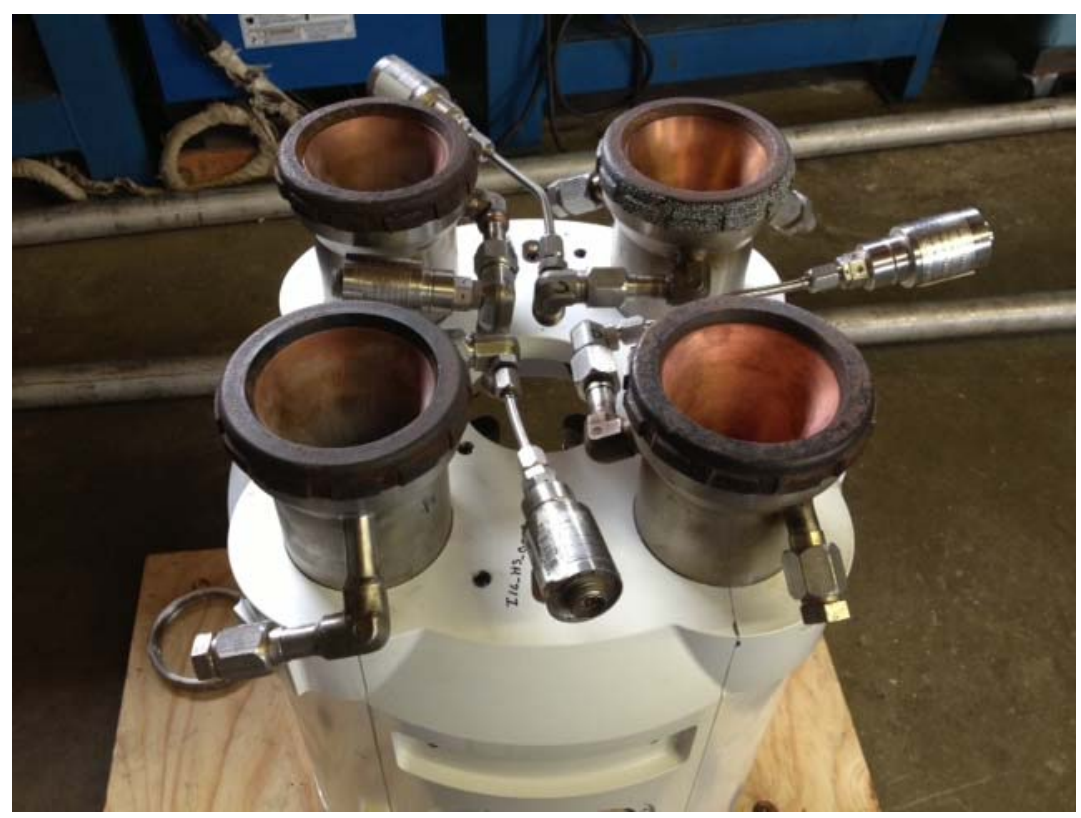




\section{Forward Work - CFD}

- Forward Work

- SMAT acoustic environments assessments

- CFD team currently generating plume models for plume studies and model verification

- CFD based acoustic prediction model development

- Acoustic environments scaling and predictions
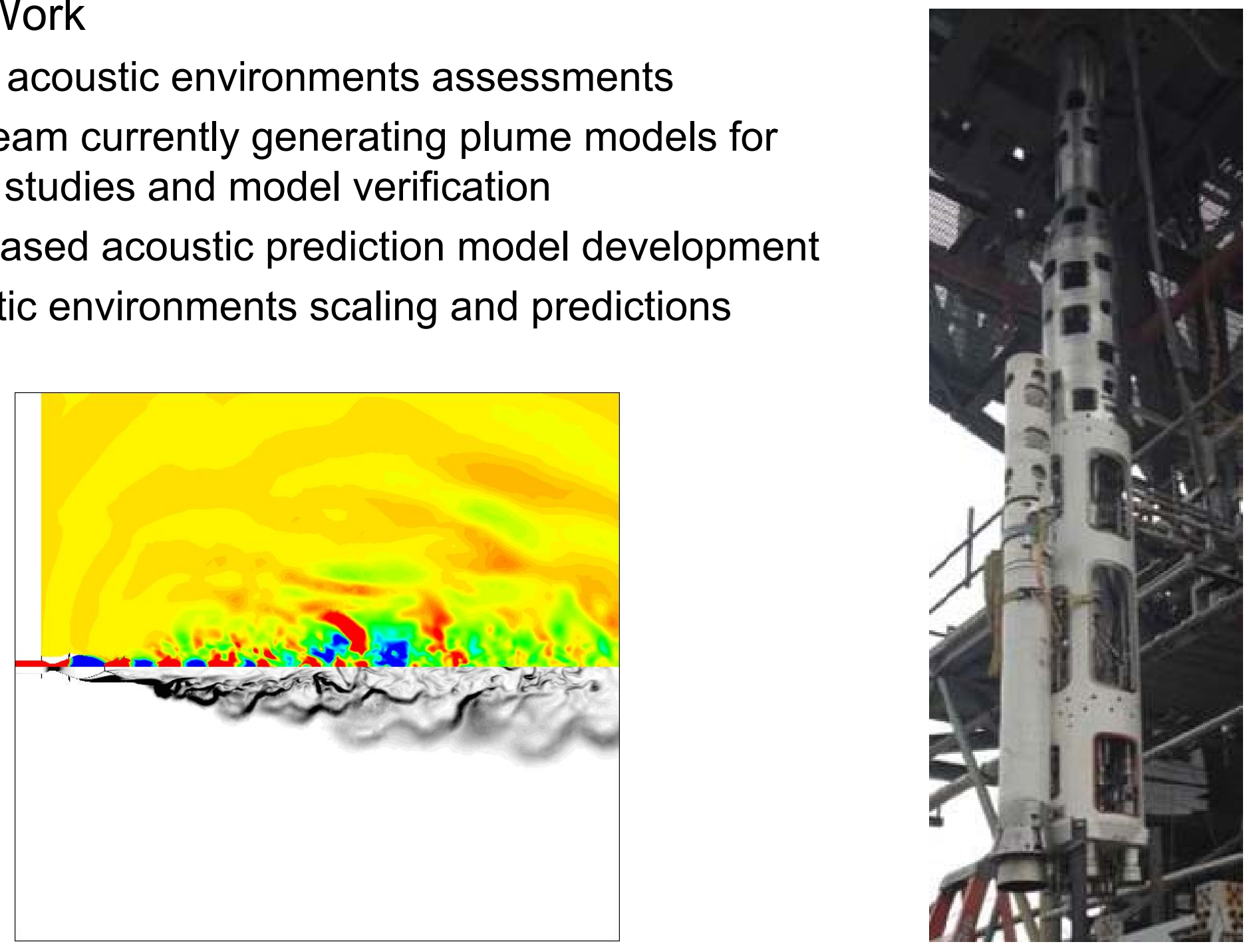

R. J. Kenny / M. Vargas 


\section{Questions?}

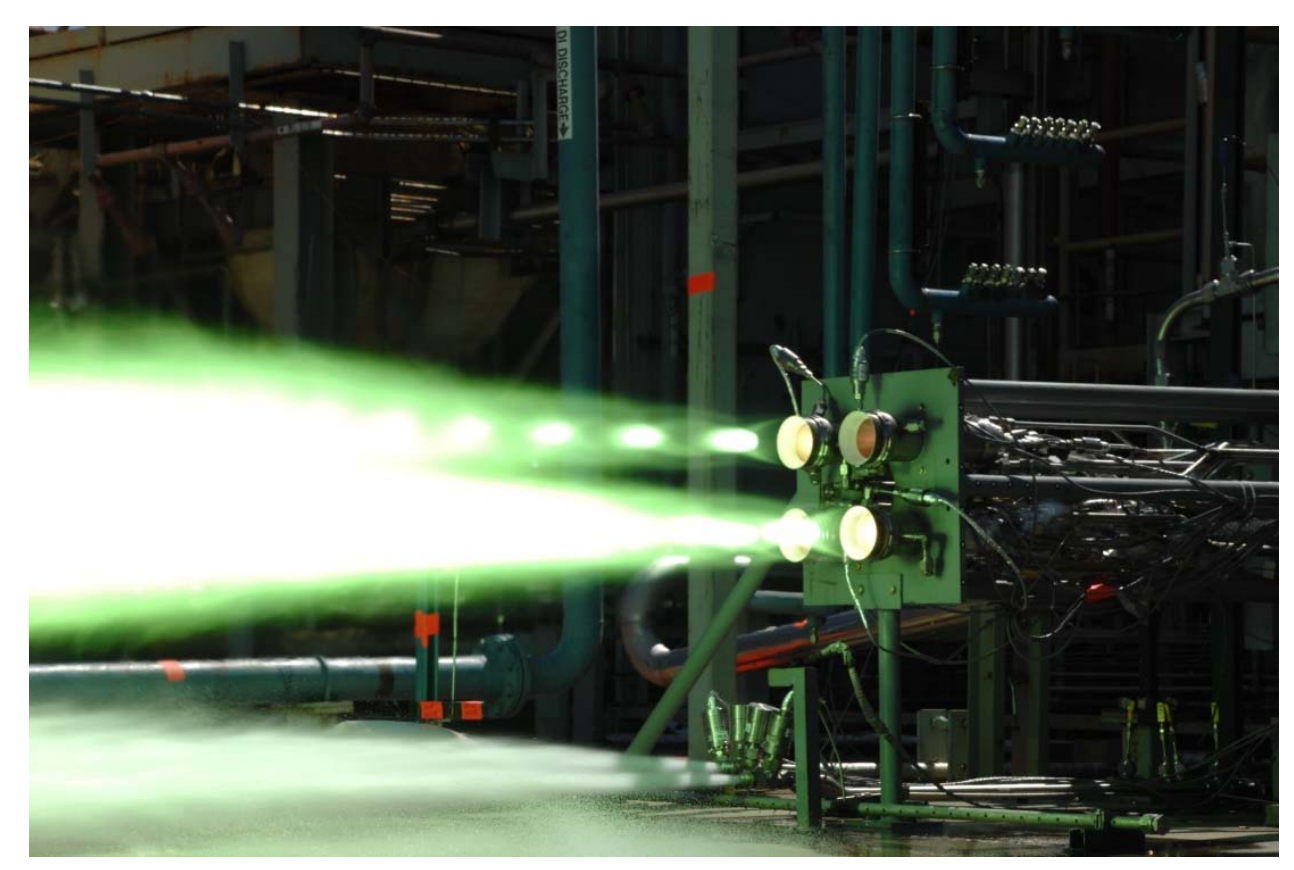

